\title{
Toward a Normative Framework for Public Health Ethics and Policy
}

Manuscript title: Toward a Normative Framework for Public Health Ethics and Policy

Running Head (only use if full title is too long): Public Health Ethics and Policy

Author: Dr James Wilson

Comprehensive Biomedical Research Centre and

Centre for Philosophy, Justice and Health

UCL

Keywords: Complex systems, Ideal Theory, Institutional Reform, Justice, Health Policy

Address:

UCL

First Floor, Charles Bell House

67-73 Riding House Street

London W1W 7EJ

Tel: +44 (0)20 76799417

Fax: +44 (0)207679 9426

Email: james-gs.wilson@ucl.ac.uk

\footnotetext{
ABSTRACT

This paper aims to shed some light on the difficulties we face in constructing a generally acceptable normative framework for thinking about public health. It argues that there are three factors which combine to make theorising about public health difficult, and which when taken together defeat simplistic top-down and
} 
bottom-up approaches to the design of public health policies.

The first factor is the problem of complex systems, namely that the distribution of health both affects and is affected by the distribution of other goods. The second is the difficulty of defining the goals of public health: we still need to get clear about what we should mean by health in this context, and what the goals of public health should be. The third is that we stand in need of an account of how important health is relative to the importance of other goods which a just society should be trying to secure for its citizens.

The paper argues that these problems should lead us to abandon the search for a 'one-size fits all' normative framework for thinking about public health. Rather, different approaches will be appropriate at different levels of abstraction.

\section{INTRODUCTION}

It is generally agreed that we still stand in need of an appropriate normative framework for addressing the ethical problems which arise in the design and implementation of public health policies. This makes the perceived situation in public health ethics rather different from the perceived situation in conventional bioethics, where a combination of Beauchamp and Childress's four principles, Mill's harm principle, and Parfit's thinking on nonidentity are taken to comprise a widely accepted paradigm within which many staple topics such as euthanasia, abortion and enhancement can fruitfully be addressed. ${ }^{1}$ This paper aims to make some modest progress towards such a framework for normative thinking about

1 I argue below that this confidence in the normative framework of bioethics is at least partially misplaced. Insofar as bioethics aims to guide public policy, it faces the same three problems we shall identify for normative thinking about public health. 
public health. It aims only for modest progress, because its chief aim is to get clear about precisely which elements of public health make it difficult to theorise, and why.

The underlying question which this article examines is the appropriate relationship between abstract philosophical thinking about public health, and public health practice. It is easy for philosophers to think that something like a top-down approach will suffice. ${ }^{2}$ On such a view, philosophers and philosophically minded ethicists reason out the appropriate goals of public health practice and the acceptable limits of state intervention in health promotion through a mixture of normative argument and conceptual analysis, and public health professionals then conform their actions to these policies. It is tempting for public health practitioners, from their more engaged perspective, to think that a bottom-up approach will suffice. On such a view the real work is to be done on the ground, and all the conceptual and ethical issues which philosophers might raise are peripheral to how the practice of public health should go on.

This article reveals along the way the distinctive weaknesses of top-down and bottom-up approaches to public health. I shall argue that there is no way to perform the easy division of labour between theorisation and implementation which the top-down approach presupposes, and that it is false to think, as the

2 By a top-down approach, I mean roughly what Caplan defined as the 'engineering model' of applied ethics, namely one which presumes that "(1) there is a body of knowledge concerning ethics that persons can be more or less knowledgeable about; (2) this knowledge becomes 'applied' in medical settings by: (a) deducing conclusions from theories in light of relevant empirical facts and descriptions of circumstances and (b) analyzing properly the process of the deduction (i.e., watching for logical fallacies, ambiguities in the meaning of key terms, improper classifications of entities, misdescriptions, etc.); and (3) the process of applying ethical knowledge to moral problems in medicine can and must be carried out in an impartial, disinterested, value-free manner." (Caplan 1983, p. 314) 
bottom-up approach presupposes, that public health policy can do without explicit and rigorous philosophical theorising. However my main aim is not to argue for the inadequacy of either of these models (which I think would not be a very challenging task), but to get a greater understanding of the problems involved in integrating more philosophical and more policy oriented perspectives in public health.

I argue that there are three important complications which we need to take into account when thinking about our normative framework for public health. The first difficulty is one which particularly affects attempts to go from philosophical ethical theorising into practicable and defensible policy. I call this the problem of complex systems, namely that the distribution of health both affects and is affected by the distribution of other goods. These interactions are not just complicated, they are complex: they outwit (and can be expected to continue to outwit) our best attempts to understand the minutiae of the relevant causal interactions. (Edwards, 2004, p.16) This creates a problem for top-down approaches to public health policy making, in as much as it will always for the foreseeable future be very difficult (if not impossible) to set and then implement policy in a way which reliably leads to things turning out as we envisage that they will, and attempts will to do so will tend to be subject to unintended adverse consequences.

The second and third problems will particularly affect bottom-up attempts to construct public health policy without drawing on deep and systematic normative reflection. The second problem is the problem of the limits and goals of public 
health. It seems intuitively obvious that the main purpose of public health policy should be to improve and protect the health of the population. However, it is far less obvious what we should take health to be in this context, and different answers will make important differences in how we view the goals of public health. Moreover, it is unclear whether the goals of public health activity ought to be simply to maximise population health, or should also include health equity and personal choice.

The third problem is the problem of the relative importance of health. I argue that health looks to be at best one ultimate good amongst several which societies should be pursuing; and it is not always the case that a policy which will further the goals of public health will also be in concert with other ultimate goals we will have as a society. In other words, we face a tough indexing problem of how to tradeoff between goals which are apparently at least partially incommensurable. Given the causal entanglement of health and other goods and the broader problem of complex systems, it does not make sense to try to set public health goals without reference to a larger framework in which we relate the value of health to the value of other goals that a society wishes to pursue.

Given the great complexity introduced into the normative regulation of public health by each of these three problems, the conclusion reached in the paper about the appropriate normative framework for thinking about public health is fairly tentative. The main conclusion reached is that whilst public health policy needs to address all of these problems, the kind of desiderata we have for solving the second two problems are dissimilar to those for solving the first. It follows that it 
is unrealistic to think that we will be able to construct a 'one-size fits all' normative framework for thinking about public health. Rather, we will do better to think in terms of what the best approach to a given problem in public health is for a given level of abstraction.

At the highest level of abstraction, the proper goals of public health activity should be closely circumscribed by what turns out to be the best theory of justice. I argue that health will be at best one good amongst others in our best account of justice: we should adopt a pluralistic account of justice as our normative framework for thinking about public health. However, when we approach closer to the real world and want to adopt a less abstract framework, there can and will be good reasons for framing the proper goals of public health activity in different terms; not so much in terms of the application of an overall theory of justice, but rather through a series of more contextual decisions about how best to proceed given the circumstances.

\section{NORMATIVE THEORISING AND THE PROBLEM OF COMPLEX SYSTEMS}

The problem of complex systems is one which is endemic to any endeavour to reform institutions, though it is one which is particularly problematic for public health interventions. In short, any attempt to change the way that an institution operates will tend to have effects on other aspects of the way this institution operates; and it will also tend to have spreading and somewhat unpredictable effects on the way that other institutions operate. To put the problem in a slightly 
different way, large institutions, such as a nationalised healthcare system, are not merely complicated, but also complex systems: it is not just that they are comprised of many parts, but also that they are comprised of parts whose interactions make a large difference to how the system as a whole operates. Moreover, these interactions between the parts do not tend to be additive: rather we also see complex positive and negative feedback loops. A set of new ideas, such as those which we now call Evidence Based Medicine, may start in a small group, then spread to a hospital, and then colonise much of medical education. Other ideas and theories, perhaps no less intrinsically helpful encounter initial turbulence, and are snuffed out.

Chapman (2004) argues plausibly that we will tend to see three large problems if we treat a complex system such as the UK's National Health Service as being amenable to a top-down engineering model of reform. First, we will tend to find that many of our reforms have unintended consequences: we will apply a reform which is intended to have one effect, but we will find that, whether it achieves its intended target or not, it also has unintended side effects. ${ }^{3}$ The second problem follows on from the first: top-down attempts to reform complex systems will tend to alienate professionals who work inside these institutions, because, given the impossibility of constructing a plan which will require sensible things in all cases, it will require the professionals to sometimes or perhaps regularly work according to goals or targets which they believe to be wrong or mistaken. For instance, a

3 The most well-known of such unintended side-effects in reform of institutions is probably the effect of setting multiple and specific targets, for instance which will tend to create incentives to meet and to prioritise the targets, and thus sideline other goals which are also important. 
doctor may be required to spend less time with a patient than she thinks necessary, because she has been instructed to see a certain number of patients per hour. Third, we can expect such reforms to fail to improve standards over time: the failures to achieve intended aims, and the need to counteract the unintended consequences of previous reforms, will lead to a perceived need for further reform, "following in the trail of events like a boxer who covers the body part that has just been hit only to get hit somewhere else." (Demosthenes, 4th Century BCE) This continual reform will of course only tend to heighten the sense of alienation felt by professionals, and will tend to add to this alienation a sense of confusion and reform fatigue. ${ }^{4}$

\section{The Inadequacy of Bioethicists' Attempts to Address the Problem of Complex Systems}

Insofar as bioethicists attempt to address questions of institutional reform - which they clearly are when for example, they address questions like whether we should enact an 'ethical market' in organs, or whether we should allow commercial surrogacy - they ought to take the problem of complex systems into account. However, bioethicists have thus far shown a rather disappointing lack of willingness to engage with this problem, and it would scarcely be an exaggeration to say that much of philosophical bioethics proceeds as if this problem did not

4 See for example, Sennett (2008, p.50): “Any organisational reform takes time to 'bed in'; people have to learn how to put the changes into practice - whom now to call, which forms to use, what forms to follow. If a patient is having a heart attack, you do not want to reach for your 'Manual of Best-Practice Performances' to discover the latest rules about what you are supposed to do. The process of bedding in takes longer the bigger and more complex the organization in which one works." 
exist. $^{5}$

There are two chief methods by which bioethicists attempt to skirt around the problem of complex systems. The first way is focusing on the moral quality of the action which will be either encouraged or discouraged, enabled or banned by the proposed reform, and assuming that the appropriate reaction to the actual implementation of the reform can be somehow read off from the moral quality of the actions involved. In certain cases, where there are strong reasons for thinking that an activity is morally impermissible, considered in itself, then it may be reasonable to take this impermissibility as giving us sufficient reason to oppose any policy which allows it. For instance, were we faced with a wrong as egregious as that of slavery, it might be claimed that there would be little point in worrying about the internal workings of institutions: we should simply get rid of slavery. And it might also be added that it will also be useful to know whether the activity in question is morally impermissible, as this will typically alter the way we interpret any apparent benefits which directly follow from the activity. ${ }^{6}$

Be that as it may, it is important to note that even in cases where an activity is uncontroversially morally wrong (such as racial discrimination) we will still face the problem of complex systems in trying to dismantle it; and unless we understand, and factor into our account, the ways in which such oppressive

5 I take it that public health ethics is sufficiently new that it would be unfair to make sweeping claims of this kind about it. My point here is that in working out a normative framework for public health ethics, it is important that writers in public health ethics not to make the mistake of thinking that they can draw on the needed accounts of institutional reform from the literature of bioethics.

6 For example, if a torturer gets pleasure out of his work, this should not count in favour of a policy which allows torture. 
institutions are maintained and supported, our attempts at reform are likely to be at best partially successful.

Where the conclusion of a bioethical argument is that an action is, considered in itself permissible, then it is even more difficult to evade the problem of complex systems. Where several different actions or reforms are permissible, it is vital to include the systemic effects of each of the potential reforms in our analysis of which policy we should favour. Depending on the bioethicist's moral orientation, more or less actions will be able to be ruled out as impermissible in themselves, and if the bioethicist's overall orientation is consequentialist, then all actions will be, considered in themselves permissible. Hence, consequentialist approaches will be especially prey to the problem of complex systems. (Lenman, 2000) Given that neither knowing that an action is impermissible nor that it is permissible will give us enough information to decide on what policy we should adopt, it follows that merely examining the permissibility or otherwise of actions considered in themselves, is very limited as a basis for thinking about the reform of institutions. ${ }^{7}$

Perhaps because of a vague awareness of this problem, when bioethicists wish to make public policy recommendations, very often they supplement the focus on moral permissibility with an appeal to one or more 'bridging principles', in order to generate public policy recommendations. ${ }^{8}$ I call this the second strategy. Such

7 None of this is to deny that arguing about whether a given activity is permissible, considered in itself, is not worth doing. It is rather that knowing that something is permissible does not tell us enough to realise whether, given our current situation, and the other institutions which are in operation, we should reform things in this way rather than a different way.

8 I have borrowed the term 'bridging principle' in this context from Habermas, but have 
'bridging principles' include the principle of least restrictive alternative, the precautionary principle and (as it is frequently used in bioethics) Rawls's difference principle. In perhaps the most common incarnation of this strategy, Mill's 'harm principle' ${ }^{9}$ is used as a way of getting from philosophical judgements about harm and permissibility to public policy in the following way:

1. We should criminalise an activity only if it involves harm to those other than those who are involved in it and consent to it. (The harm principle)

2. Doing $X$ (e.g. allowing sales of kidneys; allowing genetic enhancement) does not involve any harms to people other than consenting adults.

\section{Therefore X should be legal.}

However it is far from clear whether (and if so how) such bridging principles can solve the problem of complex systems. Are they supposed to be sound in virtue of their consequences, such that judging in accordance with the bridging principle can give us a short cut through the difficulties of reforming complex systems? If so, we would expect rather more empirical evidence than we typically see as to why this bridging principle really does allow us to cut through the immensely difficult task of reforming complex institutions. Or if they are

transformed it somewhat in the process. See for example Habermas 1990, p.63: "In theoretical discourse the gap between observations and general hypotheses is bridged by some canon or other of induction. An analogous bridging principle is needed for practical discourse. Accordingly, all studies of the logic of moral argumentation end up having to introduce a moral principle as a rule of argumentation that has a function equivalent to the principle of induction in the discourse of the empirical sciences."

9 "The sole end for which mankind are warranted, individually or collectively in interfering with the liberty of action of any of their number, is self-protection. That the only purpose for which power can be rightfully exercised over any member of a civilized community, against his will, is to prevent harm to others. His own good, either physical or moral, is not a sufficient warrant." (Mill, 1861) 
supposed to be sound for some other morally relevant reason than their consequences, one would again expect to see rather more moral argument in their favour than appears to be usual. ${ }^{10}$

In addition to such bridging principles, bioethicists also typically rely (often largely implicitly) on a philosophical anthropology: assumptions about human nature are fed in, in order to license what remain largely intuitive predictions about what would happen if a particular piece of reform were enacted. Because such philosophical anthropologies are usually kept implicit, we often see wildly different estimates about what the actual effects - both direct and indirect - of a given reform will be. A good example is provided by the debate on whether legalising euthanasia does or would lead to a slippery slope. (Lewis 2007).

\section{Public Health and the Problem of Complex Systems}

I take it therefore that the general problem we have uncovered relates to all attempts to reform institutions; and thus to the extent that traditional bioethics takes itself to be interested in the reform of institutions, it is a failing of bioethics that so little thought has thus far been addressed to it.

The problem of complex systems is even more vital to address in public health ethics, for two reasons. First, because public health interventions are classically oriented at a population level rather than an individual level, the core of public health interventions is creating and reforming institutional structures in such a

10 Unthinking application of such bridging principles is of course particularly problematic in the case of public health ethics, where what has usually been taken to be legitimate public health activity can often be taken to fall foul of the limitations on legitimate state action that Mill's harm principle would seem to recommend. 
way as to improve population health.

Second, we now have solid evidence that a vast array of different factors about the makeup of the basic institutions of society pervasively affect population health. ${ }^{11}$ We cannot improve population health without engaging deeply with the structures of these other institutions and the different ways they impact on health. Just to give one small example, (and of course, part of my point is that there will be lots of other interactions which we either do not know about yet, or which will interact unpredictably with one another), our transport and urban policy will have a great impact on health. If we encourage car use, then more people will end up obese than if we encourage cycling and walking. Hence things like the ways we design our towns (whether we place shopping centres out of the centre of town, so that it is very inconvenient to shop unless you have a car), can make a big difference to population health. On the other hand, the way we regulate the distribution of health pervasively affects the distribution of other goods. When people do not have a certain modicum of health, they are unable to work, and are thus deprived of access to other important goods (e.g. work, play, pain free existence).

An additional problem which normative thinking about public health will need to come to terms with is that the typical structure of government departments creates another layer of difficulty in constructing an effective public health policy. Even if we were in a position to understand all (or enough of) the relevant causal pathways, health ministries are not typically in a position to ensure that the

11 Out of a massive literature, see for example, Wilkinson and Marmot (2003), CSDH (2008). 
required changes are implemented in sectors such as transport, employment and education, which are usually the responsibility of different government departments. Where we need different bits of government working together in order to ensure a particular result for health, then the typical structure of government departments, which tend to be in competition with one another for resources and prestige make this difficult to achieve, and it is very likely that another department's policy may end up undermining what we would like to achieve from a public health perspective.

The problem of complex systems thus presents a serious challenge to any form of abstract theorising about public health which is not grounded in an understanding of factors which impede or accelerate our attempts at reform. In short, unless we can factor in a sufficient understanding of the inner wiring of the complex systems we are trying to reform, our attempts as philosophers to suggest how institutions should be reformed will either be dismissed as unworkable by those who are responsible for delivering services on the ground - or perhaps worse! - they may be implemented, and cause the unintended consequences and alienation of professionals which we saw are the likely results of top-down attempts to reform complex institutions. I shall suggest later that the solution to this problem depends crucially on the level of abstraction at which we are working: insofar as we are interested in largely conceptual issues, then the problem need not affect us; but if we are interested in actually improving people's lives then it is of vital importance that we take it into account. 


\section{THE LIMITS AND GOALS OF PUBLIC HEALTH}

An underlying theme of this section and the next is that despite the limitations on the power of normative thinking revealed by the problem of complex systems, significant, rigorous and abstract philosophical work is necessary for any acceptable normative framework for public health policy. This section examines two perplexities about the limits and goals of public health, whilst the next section examines the relative importance of health as compared to other goods which governments should be trying to promote.

There are two distinct ways in which the phrase 'public health' is used. First to denote the health states of a particular population (so that we might say that, for instance, a high incidence of smoking in a population is bad for public health). Second, public health is often used to mean the activities we collectively undertake to ensure that the health of the population is protected and promoted. (Verweij and Dawson, 2007) I shall refer to the first as population health, and the second as public health. It is public health in this second sense that is our focus in this article.

Public health is classically concerned with interventions that are collective in two senses: they involve the concerted action of a number of people or institutions in order to bring them about; and second, they aim to improve health at a group or population level, as opposed to an individual level. Given the doubly collective nature of public health interventions, there will be various ways in which individuals can intervene to improve their own health or the health of others which do not amount to public health interventions. Ordinary clinical medicine, in 
which one (or a number) of health care professionals are aiming to benefit a single patient, does not count as public health; nor would a particular individual's decision to stop smoking: though of course the broader decision as to whether or not to have a National Health Service, or a campaign to promote smoking cessation would. $^{12}$

Given what I have just said about the problem of complex systems, it is important to notice that there is a potential ambiguity in the idea of interventions which improve population health. Such interventions could either have improvement of population health as their aim, or they could improve population health by accident or as a by-product of the pursuit of another goal. For instance, it seems very likely that if we were to flatten inequalities in income between groups by for instance increasing top rates of tax and raising the guaranteed income of every household, then this would also reduce health inequalities, and increase average life expectancy. ${ }^{13}$ If a government were to undertake such redistribution for the purposes of changing the distribution of health, then this would clearly count as a public health intervention. However, if a government were to undertake this redistribution in ignorance of the effects that it would have on health, or were solely interested in the effects on income inequality and did not care about health inequality, then we should not describe what the government did as a public health intervention, but rather an intervention which happened to have a beneficial effect on population health. Our focus here is with interventions

12 As a moment's thought about these two examples suggests, the boundaries between public health activities and private health activities will typically be somewhat porous, and it may ultimately be better to think in terms of a continuum than a bright light between the two. I shall leave these problems of the delineation of public health on one side here.

13 See for example, Wilkinson and Pickett (2006). 
which aim to improve population health.

Understanding public health activity as interventions which aim to improve the health of the population leaves open two deep questions. First, what should we take health to be in this context? And second, how should we understand the goals of public activity: are they merely to maximise population health, or should they also include distributive questions (and hence take in issues about inequalities in health), and issues about respect for autonomy?

\section{Defining Health}

The definition of health matters deeply for public health activity. Depending on how we define health, the field of public health will be correspondingly broader or narrower, and it will be more or less difficult to explain why public health should be a priority.

Health is such a multivalent concept that there are various different ways in which we can categorise accounts of it. For our purposes we can rely on a fairly standard categorisation, according to which we analyse accounts of health according to whether (a) the judgement that someone is or is not healthy essentially depends on scientifically verifiable claims about their functioning as an organic system, and (b) whether the judgement that someone is or is not healthy essentially depends on certain evaluative claims about the state of affairs in question.

Categorising in this way gives us three kinds of accounts of health. First, purely non-evaluative accounts, which argue that we should define what counts as 
healthy in a purely scientific way, without drawing on evaluative claims at all. Second, purely evaluative accounts, which argue that there are no factual constraints about what can and cannot count as unhealthy, and that the only thing common between cases of ill health is that all are disvalued. Third, there are combined (or hybrid) accounts, according to which our account of health should be grounded in a scientific account of functioning and an account of value. (Murphy 2008)

I wish to make the relatively modest claim that anything like public health activity as we currently conceive of it presupposes a combined account. This is because if we define health in a non-evaluative way (as in such as Boorse 1975 and 1997), then it becomes rather difficult to see why it should be that we should take health to be an important goal in and of itself for government action. Certainly it cannot be that health is important for its own sake; rather it must at best be because of the enabling role that health plays for other goods. However, if health plays merely an enabling role, then it looks like our focus (from the perspective of ethics and justice) should be on the provision of these other goods which are really important in themselves, and public health policy has at best a derivative importance. This is not to argue that such definitions of health are wrong, but merely to point out that they are difficult to reconcile with the type of importance which public health practitioners usually wish to place on health.

Purely evaluative accounts of health also conflict with the classical conception of public health activity, though for a different reason. On purely evaluative accounts of health (such as Reznek 1987, Cooper 2002) there are no hard 
biological facts of the matter about which states constitute health and disease; disease states are simply states which are disvalued by societies. ${ }^{14}$ On such views, there is no essence to health. This risks making the equal and opposite problem for public health activity. If there is no essence to health, and any mental or bodily state which a society disvalues could be defined as one of ill health, then it becomes deeply unclear why we should take public health seriously as an activity; why not have activity aimed at relieving whatever the sources of disvalue are?

I take it from this that any account of public health ethics which wishes to preserve the idea of public health activity as distinctively and separately important will need to presuppose a definition of health which combines both an account of disease as involving some kind of dysfunction, and the evaluative claim that there is some specific type of disvalue associated with this dysfunction for the people who have it.

\section{The goals of public health}

As Munthe (2008) argues, the traditional goal of public health was merely to improve population health, measured for example by average life expectancy. The potential problem with this is that merely looking at averages hides potentially normatively problematic variations within the distribution of health. Since the

14 Cooper's view is somewhat more nuanced than many purely evaluative accounts of disease. On Cooper's account, by disease "we mean a condition that it is a bad thing to have, that is such that we consider the afflicted person to have been unlucky, and that can potentially be medically treated." (2002, p. 271) Without the third clause, it would not be possible to distinguish ill-health from other ways in which a person might fall short of full well being. Hence the definition needs to specify "what is distinctively medical about the conditions that we expect medical personnel to treat" (Murphy 2008). However it seems compellingly difficult to do so in a way which does not already invoke the concept of disease, and it does not seem that Cooper or any other theorist of disease as purely evaluative has succeeded in this. 
Black Report in 1980, we have become increasingly aware of the extent to which there are inequalities in health, and the fact that these inequalities fall on people who are already disadvantaged for other reasons. ${ }^{15}$ Because of this, many public health practitioners have found it plausible to introduce a second goal as a key one for public health, namely a reduction in health inequalities. More recently, a third potential goal for public health has appeared on the horizon: namely health related autonomy. The point here is simple: health is only one among many goods, and it is legitimate for citizens in a liberal society to choose to value other goods above their health if they so desire. (For instance, someone might well prefer to drink a bottle of wine per day with its attendant health disadvantages, to a more abstemious intake.) Because of this factor of personal choice, it becomes apparent that perhaps the goal of public health activity should be not to promote health per se, but to provide the conditions under which people can freely choose to be healthy if they so desire. ${ }^{16}$

Both equality and the freedom for each citizen to pursue their own conception of the good are compellingly important goals from the perspective of what we think justice, and hence governments as a whole, should be aiming at. The key question for public health is whether we should consider equality in health, and personal freedom to be internal and constitutive constraints on the goals of public health, or whether the values of equality and autonomy should be thought of as

15 Department of Health and Social Security (1980). See also Marmot 2004 and Wilkinson 1996.

16 Of course, where public health policy has as its focus children and non-competent adults, or choices in adults which tend to be less autonomous such as those concerning food and alcohol, such a 'choice-centred' view of public health is markedly less attractive. In the case of children, few will doubt that public health policy should aim simply at health rather than at the freedom to be healthy. 
external constraints on public health activity. It is not clear to me what is at stake practically here; but, as we cross over to the third problem - the importance of health relative to other goods which a society should be aiming at - we shall notice that there is a theoretical benefit to thinking of them as internal constraints, in so far as we will ultimately need to provide an integrated account of justice which takes into account how health's value is related to the value of other goods. Having an account of the goals of public health which already incorporates the core values of our overall theory of justice as constituent parts will make this work of integration less difficult. (Munthe 2008)

\section{THE RELATIVE IMPORTANCE OF HEALTH}

It is vital for normative work on public health to focus on the relative importance of health - that is the importance that health has relative to other goods which a society should be aiming to promote or protect - for two reasons. First, resources which are devoted to the goals of public health cannot be devoted to the pursuit of other goals, and it is important that as a society we should be placing our resources in a position to best meet whatever our goals should be.

Second, we remarked earlier on the way in which health is causally entangled with other goods. Hence policies which we would like to pursue in order to promote other goods (such as liberty) will tend to have effects (both positive and negative) on health, and policies which we enact to promote the goals of public health will often have effects (both positive and negative) on the distribution of other non-health goods. Where we have reason to believe that the complex causal relationships are likely to rebound in a way which is favourable (where for 
example, improving women's education and literacy has many other benefits including increased health equality), then this may not be an important practical problem. However, there are cases where goals we might wish to attain in health will conflict with other goals. In such cases we face a choice between these two rival goods, and hence it will be important to work out how important health is relative to the other goods in play.

Questions about the relative weights societies should give to different goods which goods should be seen as important for their own sake, and which goods of only derivative importance from a policy perspective - are questions about justice. Hence finding a suitable normative framework for thinking about public health ethics and policy requires us, in the end to work out which account of justice we should prefer, and the importance that health should have in this account of justice. $^{17}$

There are three basic types of answers to the value of health relative to other goods. First, we could have an approach to government which either made health the only good, or lexically prior to any other good. However, this seems very implausible as an account of justice. For there seem to be goods which are important to a just society which are neither reducible to fair distribution of health achievement, nor valued only for their contribution to fair distribution of health achievement. For example, it would seem strange to describe a society which was rife with racism and discrimination, and prevented women from voting or from holding political office, but yet where fortuitously everyone had the same level of

17 I have written about this problem at greater length in Wilson 2009a and 2009b. The next few paragraphs draw on the analysis given there. 
health achievement as one which was just. Nor is it much more plausible to claim that health is the most important good that a just society should be aiming at. For this would seem to turn our commitment to health into a 'bottomless pit', as there will always be further interventions we could make which would marginally improve health, which would have to be bought at the cost of our commitment to goods other than health. ${ }^{18}$ (Dworkin 2000, p.309)

A second possibility would be to argue that health should not be an ultimate goal for governments at all; it might be that it is another good or goods (such as opportunity for welfare, or liberty, or well being) which really matter, and that health is important only insofar as it impacts on these. As I indicated earlier, certain conceptions of health will make this view more plausible than others. If we adopt a purely non-evaluative account, according to which the claim that someone is unhealthy implies no normative claim, then it will of course be plausible to think that the real normative work about determining the proper goals of society must be done elsewhere. I shall not argue against this possibility here, but shall simply point out that the viability of public health ethics as a branch of ethics, and public health as a set of activities seems to presuppose the contrary: namely that health is important for its own sake as a good and as a goal for government action.

A third possibility would be a pluralistic approach, in which more than one good was deemed a suitable goal of government policy, and health was one of

18 The World Health Organisation (WHO) definition of health, namely that health is is a state of complete physical, mental and social well-being and not merely the absence of disease or infirmity' makes it less implausible to think that health so defined could be the most important good for a just society to focus on. However this is due to the fact the definition of health is simply too all-encompassing to be useful as a definition of health. (For the debate on the WHO definition of health, see further Callahan 1973 and Bok 2004) 
these. Pluralistic approaches to government action, as I shall use the term here are defined by the fact that (a) they take more than one good to be a goal of government activity for its own sake, and (b) these goods are at least partially incommensurable.

Partial incommensurability is defined as a lack of full compensability. If two goods are fully commensurable, then it is possible (in principle) to compensate a shortfall of one in terms of giving more of the other. For instance, ten pound notes and five pound notes are very obviously commensurable in this sense: if you lend me $£ 50$ composed of five tens, and I give you back ten fives, I have fully compensated you. A good is partially incommensurable if a shortfall in it cannot be fully compensated. (Wolff and de Shalit 2007; Hausman 2007). Wolff and deShalit point out that if full commensurability about justice were true, it would follow that any disadvantage relevant to justice could be fully rectified by providing a suitable amount of this one currency. However, it seems counterintuitive to suppose that this is the case; and most people are particularly unwilling to suppose that health is fully commensurable with all other goods which a society should be aiming at. For instance, it seems difficult to see how a disadvantage such as a greatly increased risk of early death, or chronic ill health could be fully compensated by more of a non-health good. (Wolff and de-Shalit 2007, pp. 21-35)

In short, public health policy faces the following normative problem. Either health is an ultimate goal of public policy, or it is not. If it is not a suitable ultimate goal of public policy, then we should be less concerned with public 
health, and more concerned with the distribution of those goods that do matter for their own sake. If health is a suitable ultimate goal of public policy, then it seems very implausible to think that it could be the only goal of public policy. There seem to be other ultimate goals of a good society which are not reducible to health or their effects - whether direct or indirect - on health. However, if health is but one of many ultimate goals of public policy, and these goals are at least partially incommensurable, then it is far from clear how we prioritise these different goals: we will need to make tradeoffs between health and other goods, and we do not seem to have a principled way of doing this.

This problem of incommensurability interacts with the problem of complex systems in such a way that both problems are magnified. For we saw from our analysis of the first problem that (a) the way which other goods are distributed pervasively affects the distribution of health, and vice versa; and (b) we are not in a position to see the way through the complexity of the relevant causal connections, so we cannot with any confidence predict that a given measure to improve health will in fact have the effects we want it to, nor that it will not have collateral effects on the distribution of other goods. However, we can now see that things are even more complex, as there will be disagreements at the level of how to prioritise goals as well.

\section{CONCLUSION: PUBLIC HEALTH AND PUBLIC POLICY}

I have discussed three ways in which public health presents difficult challenges for normative thought. Where should we go forward from here? The best way 
forward depends on what we are trying to achieve through our normative thinking about public health. Is our primary aim to actually usefully guide public health policy? Or are we interested in a more abstract set of conceptual questions about how to define health, and how to relate the value of health to the value of other goals?

Both types of questions can be useful ones to ask; but it is important to understand that they are different ones, and that making progress in answering one will not automatically allow us to make progress in answering the other. This is most obvious in the case of the more engaged question about how to guide public health policy: clearly when we are thinking about what we in our current situation should do to improve population health in an ethically acceptable manner, this will not necessarily allow us to answer more abstract questions about what an ideal public health system would be, as our current situation may be skewed and unusual in various ways.

But perhaps less obviously, it is important to note that even if we were able to answer these more idealised questions, this would not be sufficient for solving the practical problem of where we should go from here. (Sen 2006) It will not be sufficient because the ideal account of justice may not be implementable now; and adopting a policy which presupposes rather different background conditions than the ones which obtain may lead to much worse results than implementing a different "second best" approach. (Pettitt and Brennan, 2005) Moreover, having a correct answer to the more idealised question does not seem to be a necessary condition either, as the choices we face in policy are typically comparative ones; 
out of a few different ways we could take policy, we want to know which one to opt for, and knowing how to answer this question will not require us to know what the best policy out of all possible policies would be. (Sen 2006)

If anything comes out of this examination, it is the need for flexibility, and the thought that when we are thinking about public health, one size does not fit all. Problems which are conceptually tough, and perhaps even insuperable (such as ranking incommensurable values) can often be of only marginal relevance for practice; and things which are conceptually simple (like reducing rates of obesity) can be very difficult in practice.

We can approach problems in public health at different levels of abstraction. At the highest level of abstraction, the proper goals of public health activity should be closely circumscribed by what turns out to be the best theory of justice. However, when we approach closer to the real world and want to adopt a less abstract framework, there can and will be good reasons for framing the proper goals of public health activity in different terms, and it will not usually be appropriate to think of practical issues in public health as an exercise in applying theories of justice. First of all, what justice overall requires is typically controversial, and so we will not be able to look to anything like an uncontroversial account of justice in order to reveal to ourselves what we should do. Second, the correct solution for an ideally just society will not necessarily be more helpful for us in our imperfect society than a rather more pragmatic approach. Third, when we are deciding what to do in terms of public health policy, we will not typically be in a position to alter and tweak all other parts of public 
policy. Despite what governments may claim about the need for joined up thinking', much policy making remains confined to silos, and practical policy making will need to be aware of this.

\section{REFERENCES}

Department of Health and Social Security. (1980). Inequalities in health: report of $a$

research working group. London: DHSS, 1980.

Bok, S. (2004). 'Rethinking the WHO Definition of Health', in Harvard Centre for Population and Development Studies: Working Paper Series, 14(7).

Boorse, C. (1975). 'On The Distinction Between Disease and Illness,' Philosophy and Public Affairs, 5: 49-68.

Boorse, C., (1997). 'A rebuttal on health,' in J. M. Humber and R. F. Almeder (Eds.), What is disease? Totowa, NJ: Humana Press, pp. 3-143.

Brennan, G. and Pettit, P. (2005). 'The Feasibility Issue', in Oxford Handbook of Contemporary Philosophy, edited by F. Jackson and M. Smith. Oxford: Oxford University Press, pp. 258-282.

Callahan D. (1973). 'The WHO Definition of "Health".' Hastings Center Studies, 1(3), 77-87.

Caplan, A. (1983). 'Can Applied Ethics Be Effective in Health Care and Should It Strive to Be?', Ethics, 93(2): 311-319. 
Chapman, J. (2004). System Failure: Why governments must learn to think differently (second edition). London: Demos. Available from http://www.demos.co.uk/publications/systemfailure2.

Cooper, R. (2002). 'Disease', Studies in History and Philosophy of Biological and Biomedical Sciences, 33: 263-282.

CSDH (2008). Closing the gap in a generation: health equity through action on the social determinants of health. Final Report of the Commission on Social Determinants of Health. Geneva, World Health Organization.

Demosthenes (4th Century BCE), First Philippic.

Dworkin R. (2000). Sovereign Virtue: The Theory and Practice of Equality. Cambridge, Mass.: Harvard University Press.

Edwards, N. (2004). 'Foreword', in Chapman, J. (2004), System Failure: Why governments must learn to think differently (second edition). London: Demos. Available from http://www.demos.co.uk/publications/systemfailure2.

Habermas, J. (1992). Moral Consciousness and Communicative Action, trans. C. Lenhardt and S. Nicholsen. London: Polity Press.

Hausman, D. M. (2007). 'What's wrong with health inequalities?', Journal of Political Philosophy, 15(1), 46-66.

Lenman, J. (2000). Consequentialism and Cluelessness. Philosophy and Public Affairs, 29(4), 342-370.

Lewis, P. (2007). 'The Empirical Slippery Slope from Voluntary to Non- 
voluntary Euthanasia?', Journal of Law, Medicine, and Ethics, 35(1), 197-210.

Marmot, M. (2004). Status Syndrome: How Your Social Standing Directly Affects Your Health and Life Expectancy. London: Bloomsbury.

Mill, J. S. (1861). On Liberty.

Munthe, C. (2008). 'The Goals of Public Health: An Integrated Multidimensional Model', Public Health Ethics, 1(1), 39-52.

Murphy, D. (2008). 'Concepts of Disease and Health', The Stanford Encyclopedia of Philosophy (Winter 2008 Edition), Edward N. Zalta (ed.), URL = <http://plato.stanford.edu/archives/win2008/entries/health-disease/>.

Reznek, L., (1987). The Nature of Disease, New York: Routledge.

Sen, A. (2006). 'What do we want from a theory of justice?', Journal of Philosophy 103(5), 215-238.

Sennett, R. (2008). The Craftsman, Allen Lane: London.

Verweij M. and Dawson A. (2007) 'The meaning of "public" in public health', in M. Verweij and A. Dawson eds. Ethics, Prevention and Public Health, Oxford: Oxford University Press.

Wilkinson R. and Marmot M. (2003) Social Determinants of Health: The Solid Facts. Denmark: World Health Organisation. Available from http://www.euro.who.int/document/e81384.pdf

Wilkinson R. (1996). Unhealthy Societies: The Afflictions of Inequality. London: Routledge. 
Wilkinson, R., Pickett, K. (2006) 'Income inequality and population health: a review and explanation of the evidence'. Social Science and Medicine 62, 17681784.

Wilson J. (2009a). 'Not So Special After All? Daniels and the Social Determinants of Health', Journal of Medical Ethics 35(1), pp. 3-6.

Wilson J. (2009b). 'Health Inequities', in A. Dawson ed. Public Health Ethics: Key Concepts in Policy and Practice. Cambridge: Cambridge University Press.

Wolff, J. and de-Shalit A. (2007). Disadvantage. Oxford: Oxford University Press.

\section{Funding Statement}

This work was undertaken at UCLH/UCL who received a proportion of funding from the Department of Health's NIHR Biomedical Research Centres funding scheme.

\section{Acknowledgements}

Earlier versions of this paper were presented at Manchester Metropolitan University and University College London. Thanks to both audiences for comments and criticisms. I would like in particular to thank Alan Cribb, Angus Dawson, Sarah Edwards, David Hunter, Milena Nuti, Shepley Orr, Sridhar Venkatapuram and Jonathan Wolff. 